\title{
Self-Esteem and Delinquency Revisited
}

\author{
John M. Bynner, ' Patrick M. O'Malley, ${ }^{2}$ and Jerald G. Bachman ${ }^{3}$
}

Received July 24, 1981

A recent investigation by Rosenberg and Rosenberg used longitudinal data from the Youth in Transition study to explore the causal relationships between delinquency and self-esteem. The present study is based on the same sample of young men in high school and extends Rosenberg and Rosenberg's analysis, first by using the same cross-lagged correlation methods applied over a longer time period, and then by employing a "causal modeling" approach using the LISREL computer program. Each of the analyses was carried out using the total sample as well as two subsamples, the highest and lowest quartiles in initial self-esteem. The causal modeling analyses attempted (a) to take careful account of the actual periods referenced by the measures of delinquency and self-esteem, (b) to control socioeconomic status and ability, and (c) to extend the model to demonstrate ways in which participation in teenage social life and current educational attainment might also influence and be influenced by self-esteem. The analyses suggest that self-esteem plays little part in influencing the teenage behaviors and orientations that follow in time. Consistent with Kaplan's prediction, among young men who enter high school with low self-esteem, the effects of delinquent behavior tend primarily to be self-enhancing.

This research was supported by an Open University Research Grant awarded to John Bynner while a Fulbright-Hays Scholar at the Institute for Social Research, University of Michigan. 'Senior Lecturer in Educational Studies, The Open University, Great Britain. Completed his first degree in Psychology at the University of Bristol and his doctorate at the University of London. Main research interests are adolescent values and research methodology.

${ }^{2}$ Study Director and Assistant Research Scientist, Survey Research Center, Institute for Social Research, The University of Michigan, Ann Arbor. Received his Ph.D. from the University of Michigan. Main research interests are youth and social issues and developmental psychology.

${ }^{3}$ Program Director and Research Scientist, Survey Research Center, Institute for Social Research, The University of Michigan, Ann Arbor. Received his Ph.D. from the University of Pennsylvania. Main research interest are studies of youth and social issues. 


\section{INTRODUCTION}

In a recent analysis of self-esteem and delinquency, F. Rosenberg and Rosenberg (1978a) pose a key theoretical question: "Does self-esteem cause delinquency or delinquency self-esteem?" They attempted to answer this question by using data from Youth in Transition, a longitudinal study of adolescent boys (Bachman et al., 1978). In the present paper we consider the same basic question using the same data set-with a wider range of variables and a longer longitudinal span. Our consideration of the theoretical issues and also the nature of the available data have led us to analysis approaches and findings somewhat at variance with those reported by Rosenberg and Rosenberg.

Heavily influenced by the earlier work of M. Rosenberg (1965) and Coopersmith (1967), we use the term "self-esteem" to refer to an individual's self-evaluation of his/her own worth; we treat it as a global dimension; and we view it as having some enduring properties, rather than as shifting abruptly from one situation to another. Now let us consider the ways in which delinquency is theorized to be related to global self-esteem.

Hypothesis 1 is that delinquent behavior leads to a reduction in selfesteem. Following the interactionist view of delinquency stemming from Mead (1934), reduced self-esteem can be seen as the product of "reflected appraisal." F. Rosenberg and Rosenberg (1978a) summarize this theoretical perspective as follows: The deviant individual, "taking the role of the other, sees himself through the eyes of particular others or from the perspective of the generalized other. He tends not only to internalize the negative attitudes of particular other people toward the self but also, feeling that he violates the basis values of the society, comes to share society's negative attitudes toward himself (i.e., to develop low self-esteem)" (p. 21).

Hypothesis 2 states that low self-esteem leads to an increase in delinquent behavior. Faced with increasing conflicts between the roles demanded of them at home, at school, and in the peer group, many teenagers find their self-esteem under severe strain. They seek ways of enhancing their status with their peers, and many writers have interpreted the onset of the delinquent or deviant behavior in the early teens as serving this purpose (Cohen, 1955; Cloward and Ohlin, 1960; Matza, 1964; Downes, 1966; Elliott and Voss, 1974; Kaplan, 1975, 1977, 1978; Gold, 1978). Thus Kaplan (1975), in probably the most detailed examination of the role of self-esteem in delinquency, argues that a build-up of negative feelings in teenagers brought about by continued failure to meet the standards expected of them in their dominant membership groups impels them to seek the company of teenage groups where these standards are rejected and delinquent behavior is admired. By endorsing delinquent values and living up to them through the commission of delinquent acts, the teenager gains the status that is denied in 
other settings, and consequently self-esteem is restored. But this notion that low self-esteem prompts delinquent behavior as a means for restoring selfesteem implies a third hypothesis.

Hypothesis 3 states that under some conditions-specifically, low initial self-esteem-delinquent behavior leads to an increase in self-esteem. The rationale for this hypothesis is spelled out above, and is indicated clearly in the summary of Kaplan's theory provided by F. Rosenberg and Rosenberg (1978a) "The low self-esteem person thus engages in delinquency both in order to retaliate against the society which disdains him and in order to gain a much needed feeling of self-esteem" (p. 21). Nevertheless, this third hypothesized relationship, the "other side of the coin" in Kaplan's theory, seems not to have been taken into account in Rosenberg and Rosenberg's efforts to sort out the causal connections between self-esteem and delinquency. (McCord, 1978, made essentially this point in a critical comment on their research; also see their rejoinder, Rosenberg and Rosenberg, 1978b.)

It should now be clear that the theorizing about self-esteem and delinquency is quite complicated, and a considerable range of empirical predictions is possible based on various combinations of the above hypotheses. Hypotheses 1 and 2 both imply a negative correlation between the two variables, but Hypothesis 3 implies a positive correlation for a subgroup initially low in self-esteem. Hypotheses 1 and 3 treat delinquency as a cause of self-esteem; the reverse is true for Hypothesis 2. Finally, Hypotheses 2 and 3 go hand in hand and cannot be separated from each other - at least not if we are to follow Kaplan's line of theorizing.

Rosenberg and Rosenberg's analysis was an effort to distinguish between Hypotheses 1 and 2, using a cross-lagged correlational analysis of data collected in the Youth in Transition study (Bachman et al., 1978), a longitudinal survey involving five waves of data collection from a nationally representative United States sample of boys entering senior high school. Data were first collected in 1966 when the boys were in the sophomore year (average age 15), then again in 1968, 1969, 1970, and 1974. In support of Kaplan's theory, Rosenberg and Rosenberg were able to show that the cross-lagged negative correlation between self-esteem at the first data collection (time 1) and delinquency at the second data collection (time 2) was stronger than the negative correlation between delinquency (time 1) and self-esteem (time 2). These differences were strongest for boys from the families in the lowest socioeconomic groups. From these findings Rosenberg and Rosenberg concluded that causality runs more strongly from selfesteem to delinquency (Hypothesis 2) than vice versa (hypothesis 1).

Evidence for Hypothesis 3 (the "self-enhancing" effects of delinquency) is more difficult to come by. However, in certain restricted subgroups, relationships in line with Kaplan's theory have been demonstrated. 
Thus, in a reanalysis of data from the 1967 National Youth Survey, Gold and Mann (1972) showed that among highly delinquent groups the positive correlation between self-esteem (as measured by a questionnaire) and educational attainment disappears. Kaplan (1978) presents some direct evidence in favor of his theory, demonstrating from the analysis of longitudinal data (collected from 3000 boys and girls passing through 36 junior high schools) that those initially lowest in self-esteem who engaged in sustained delinquent behavior tended to show greater increases in self-esteem than those who were not delinquent. These results were based mostly on very small samples of teenagers who admitted different types of delinquent behavior; ${ }^{4}$ but in line with the theory, such results were not found for teenagers who showed moderate or high levels of initial self-esteem. Such selfenhancing effects were also found more consistently for boys than for girls, which is again consistent with the expectation that delinquent behavior has more power for bestowing status on boys than on girls.

There are four kinds of difficulties with Rosenberg and Rosenberg's results and Kaplan's theory to which they relate, which the present study attempts to rectify:

1. As noted earlier, Rosenberg and Rosenberg's analysis took no account of Hypothesis 3, which suggests a more complex interaction in which the effects of delinquency on later self-esteem are presumed to be dependent at least in part upon earlier (prior) levels of self-esteem. If both Hypothesis 2 and Hypothesis 3 are true, as Kaplan's theory suggests, then a failure to disentangle the two kinds of effects could lead to a confounding and perhaps canceling of the two different kinds of relationship.

2. Rosenberg and Rosenberg assumed "synchronicity" for the measures of self-esteem and delinquency in the Youth in Transition survey (i.e., these measures could justifiably be treated as representing occurrences at the same point in time). In reality, the time 1 delinquency measures they used spanned the whole period of junior high school, while self-esteem was measured on a scale representing current feelings at the time the Youth in Transition data were collected. Similarly, the delinquency measures at time 2 spanned the preceding period between the first two waves of the survey. This suggests that the correct relationship between self-esteem and delinquency measured at a given time (e.g., time 2) would locate delinquency prior to self-esteem in the temporal sequence. Thus, the delinquent acts during the 18 months prior to time 2 could have influenced self-esteem at time 2, but not vice versa.

"For example, of 13 "statistically significant" comparisons in Kaplan's data (1978) which showed support for the theory, 11 were based on fewer than 20 delinquent cases; 3 were based on as few as 2 cases. 
3. Although Rosenberg and Rosenberg controlled the effect of socioeconomic status (SES) in their analysis, other crucial "exogenous" variables such as intellectual ability and past educational attainment and aspirations, which might be expected to influence delinquency and self-esteem, were not controlled. Earlier analysis of the Youth in Transition data had shown that these variables are correlated with both delinquency and self-esteem (Bachman, 1970; Bachman and O'Malley, 1977).

4. The focus in previous analyses on delinquency as the response to reduced self-esteem, in isolation from other responses, disregards the other major ways in which teenagers can gain status in the eyes of their friends. A comprehensive analysis of the delinquency-self-esteem relationship needs to take these other means of restoring self-esteem into account. Thus, through reanalysis of surveys of teenage smoking, drinking, and drug taking in the United Kingdom, Bynner (1979) identified three major dimensions of teenage values - "successfulness," "toughness," and "sexual precocity"-along each of which self-esteem can be lost or gained. Teenagers who are failing at school may, for example, gain status both at school and outside by engaging in a range of adult-disapproved activities such as smoking, drinking, and delinquent acts because of their identification with "toughness"-a masculine attribute that most boys inside or outside school admire. Furthermore, the negative connotations of delinquent behavior, which reduce selfesteem, may be ameliorated by success with the opposite sex-an accomplishment which commands respect in the wide teenage culture outside the school. In addition, as Gold and Reimer (1975) argue, the significance of delinquent activities and educational success in the maintenance of self-esteem changes with age. Thus, Bachman and O'Malley (1977) showed from their analysis of the Youth in Transition data that self-esteem increases through the teens and that its relationship to other variables, especially educational attainment, weakens as boys get older (see also O’Malley and Bachman, 1979).

\section{ANALYSIS STRATEGY AND PREDICTIONS}

Having outlined the theoretical and methodological complexities facing us, we do not suggest that what follows is a totally clean and convincing test of the issues. The theorizing is too complex for that, and the data are limited in several respects. Our claims are more modest: We hope to carry the analysis of self-esteem and delinquency several steps further and to indicate some ways in which the findings are at least consistent with some of the theoretical work described above.

We begin by essentially repeating Rosenberg and Rosenberg's crosslagged correlation analysis for the total sample, expanding it by including 
time 3 measures; then, in line with Kaplan's theory, we repeat the analysis for the two subgroups initially high and low in self-esteem at time 1 (thus addressing Difficulty 1). Then, because in our view cross-lagged panel analysis is not the best way to analyze these data (see Difficulty 2 ), we turn instead to a LISREL approach (Joreskog and Sorbom, 1978, 1979) presenting a rather simple model which incorporates, in addition to self-esteem and delinquency, a limited set of control variables (see Difficulty 3 ). Finally, we enhance the model by adding measures of current educational attainment and active participation in teenage social life (see Difficulty 4).

To put both Rosenberg and Rosenberg's conclusions and Kaplan's theory to the test, we replicate each model across three groups: the sample of boys who were still in the Youth in Transition study at time 4, and two subsamples of boys in the top and bottom quartile ranges of self-esteem scores at time 1 (i.e., the time at which the boys entered senior high school). ${ }^{5}$ Rosenberg and Rosenberg's analysis was restricted to data collected in the first two waves of the survey (time 1 and time 2); we extend the analysis to include measures at time 3. They used five indicators of delinquency for their analysis: "delinquency in school," "seriousness of delinquency," "theft and vandalism," "frequency of delinquency," and "total delinquency." In order to keep an already complicated analysis within reasonable bounds, we employ two indicators: "theft and vandalism" and "delinquency in school."

The causal model provides a framework within which specific predictions can be tested. The main ones are as follows:

Prediction 1. In the total sample, the path from self-esteem to later delinquency will be consistently negative and stronger than the path from delinquency to later self-esteem. (In other words, consistent with the Rosenbergs' conclusions, we expect the data to show more support for Hypothesis 2 than for Hypothesis 1.)

Prediction 2. Among the low self-esteem group entering high school, there will be a positive path from delinquency at time 1 to self-esteem at time 2, but among the high self-esteem group the path will be negative or zero. (This is consistent with Kaplan's theory and Hypothesis 3.)

Prediction 3. Controlling for SES, ability, and past educational attainment and aspirations will change the size but not the direction of the relationships in predictions 1 and 2 .

Prediction 4. Including measures of current educational attainment and active engagement in teenage social life at each time point will help to

'Using the time 4 sample enabled us to include in other analyses not reported here data on drinking, smoking, and illicit drug use, none of which were collected prior to time 4 . 
clarify the role of reduced self-esteem in delinquency and will show any agerelated changes in the relative importance of delinquency and these other influences as methods for enhancing self-esteem.

Generally speaking, standardized coefficients are preferred for making comparisons between coefficients within groups, and unstandardized coefficients are preferred for making comparisons between groups. In this paper, we make both types of comparisons; in order to allow the reader to see both coefficients we have opted to provide standardized values in the figures, and unstandardized values in tables. In presenting the results, we utilize the coefficients most relevant for the specific cases.

The data for this report come from the Youth in Transition project, a nationwide longitudinal study of young men. Details of the design can be found in Bachman et al. (1978). The project used a multistage probability sample, clustered by school, of all tenth-grade boys in public high schools in 1966 in the 48 contiguous states. Three data collections occurred during the years when most were still in high school: in fall 1966 (early tenth grade), spring 1968 (late eleventh grade), and spring 1969 (late twelfth grade). The fourth data collection occurred in spring 1970, one year after most respondents had graduated from high school. These first four data collections consisted of interviews and/or questionnaires administered by professional interviewers on the staff of the University of Michigan's Survey Research Center. The fifth, and final, data collection was a self-completed mail questionnaire sent during spring 1974, five years after high school.

Of the original sample of 2277 boys located in 87 schools, data were collected from $2213(97.2 \%)$ in 1966. The present analyses are based upon only 1471 White respondents who participated in $1970 .^{6}$ The sample attrition has, of course, reduced the generalizability of the results. While the young men who participated in 1966 but not in 1970 differ from the retained 1471 , we believe that the retained sample is reasonably representative of the original population, particularly with regard to relationships among variables. For additional discussion and documentation of this point, see Bachman et al. (1978, pp. 257-267). We should note that because we utilize data from later waves, this sample is different from the sample used in Rosenberg and Rosenberg's analyses, which were restricted to the 1886 respondents who participated at both times 1 and 2 .

'The self-report data on delinquent behavior showed particularly large mean shifts between time 1 and time 2 for several schools, particularly two Black Southern rural schools. This shift may be due to an increase in trust held by the respondents in the interviewers, between the first and second interviews. If there were less trust at the first interview, the time 1 delinquency data are likely to be less valid for these schools; and for that reason we chose to limit the analyses for the present report to White respondents. 


\section{Measures}

Unless otherwise indicated, all measures were obtained at each data collection.

Socioeconomic status (SES), measured only in 1966 (time 1), refers to the respondent's home and family background, and is an equally weighted mean of the following six items (all scores standardized): status of father's occupation on the Duncan (1961) scale, father's education, mother's education, a checklist of possessions in the home, number of books in the home, and the ratio of rooms per person in the home.

Intellectual ability is the mean of standardized test scores obtained in 1966 on three measures of intellectual ability: Quick Test (Ammons and Ammons, 1962), Gates (1958) Test of Reading Comprehension, and the 1962 General Aptitude Test Battery - Part J, Vocabulary.

Held back is a dichotomy. The respondent was asked in 1966 whether he had ever been kept back a grade (coded $1=$ yes, $5=$ no).

Average grade is a self-report of overall average grades for the previous year, as reported in 1966, 1968, and 1969. The scale ranges from 10 (failing) to $58(\mathrm{~A}+$ ).

College plans is a dichotomy indicating whether the respondent expected to attend college after high school.

Social life, measured only in 1966 and 1968, is a mean across three items which asked how many evenings the respondent was allowed to go out for fun during the school year, and how often he went out for fun and recreation or on dates.

Self-esteem is measured by a 10 -item index adapted from those used by $M$. Rosenberg (1965) and Cobb et al. 1966). The respondent was asked to rate himself on items intended to tap a global self-evaluation, such as "I am able to do things as well as most other people" (see Bachman and O'Malley, 1977 , for more detail).

Delinquent behavior is based on self-reported frequency of delinquent acts. Respondents were asked to indicate on a 5-point scale ranging from never to five-or-more times how many times they had committed each of 26 behaviors. Delinquent behavior in school is a mean of 7 items dealing with school-based behavior; theft and vandalism is a mean of 9 items dealing with stealing, trespassing, and destroying property. Some problems with this measure must be noted. To quote Bachman et al. (1978):

The first data collection asked respondents, "Please tell us how many times you have done these things in the last three years - say since you started the seventh grade." At time 2, eighteen months later, the instruction was changed to read, "Please tell us how many times you have done these things in the last 18 months-since we last talked with you." At time 3, twelve months later, the same instruction was repeated, but, the time interval was erroneously not changed to twelve months (the 
interval since last we talked with the respondents); thus we cannot be sure how many respondents were responding to the part of the instruction which said "the last 18 months" and how many were responding to that statement "since we last talked with you."... Based on the greater wisdom of hindsight, it would have been better to use a one-year interval for all of the delinquency questions. Fortunately, our primary focus ... is on relational analyses rather than overall shifts in delinquency rates; therefore, the problems outlined above do not seriously limit our ability to draw conclusions from the data. (p. 173)

\section{RESULTS}

All subsequent analyses were carried out on the variances, covariances, and product-moment correlations (with pairwise deletions for missing data) among the above variables within and across all three time points for the total sample and the two subsamples. These three correlation matrices, along with means and standard deviations, are shown in the Appendix.

\section{The Rosenberg and Rosenberg Model and the Kaplan Model}

Figure 1 replicates the analysis initially presented by $\mathrm{F}$. Rosenberg and Rosenberg (1978a), but now expanded by adding time 3 data to cover an additional time, and extended by including groups high and low in initial self-esteem (in order to test the Kaplan hypothesis). It can be seen that for both "theft and vandalism" and "delinquency in school" in the total sample, as Rosenberg and Rosenberg concluded, the correlations between measures of delinquency and self-esteem are consistently negative, and that the crosslagged correlation between self-esteem (time 1) and delinquency (time 2) is a little stronger than the correlation between delinquency (time 1) and selfesteem (time 2) across this time period. The cross-lagged pattern is repeated, though more weakly, from time 2 to time 3.

Among the high self-esteem group (at time 1) this general pattern of negative correlations between delinquency and self-esteem is maintained, but this time there is no evidence of a stronger relationship from self-esteem to delinquency rather than the reverse. However, for the low self-esteem group, exactly in line with Kaplan's theory, the correlation between delinquency and self-esteem changes from negative at time $1(-0.25$ for theft and vandalism and $-\mathbf{0 . 1 8}$ for delinquent behavior in school) to positive at time 2 ( 0.12 and 0.06 , respectively). The cross-lagged correlations for the group initially low in self-esteem reinforce these results. Thus, although the cross-lagged correlations running from self-esteem to delinquency are all weakly negative or near zero, their counterparts from delinquency to self- 


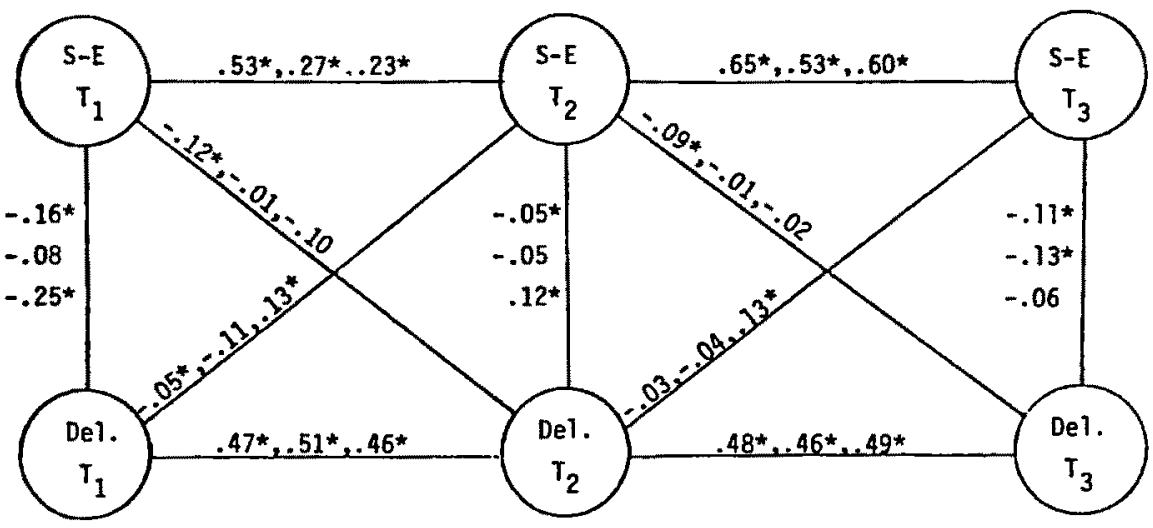

THEFT AND VANDALISM

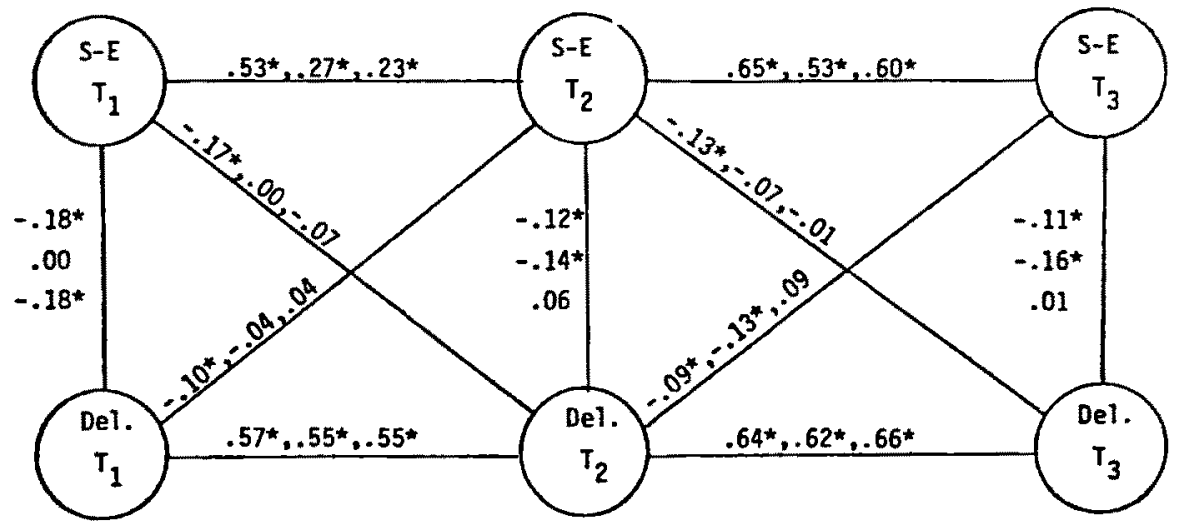

DELINQUENCY IN SCHOOL

Fig. 1. Cross-lagged correlation analysis for self-esteem and delinquency. All coefficients are product-moment correlations; the first of each three is for the total sample, the second for the high self-esteem group, and the third for the low self-esteem group. ${ }^{*}=$ correlation is more than twice its standard error. 
esteem are consistently positive. In other words, these results suggest that reduced self-esteem does lead to delinquency (Hypothesis 2) and delinquency does help to restore self-esteem (Hypothesis 3).

\section{Causal Model of the Relationship Between Delinquency and Self-Esteem} (Model 1)

As noted earlier, the cross-lagged correlation model makes certain assumptions about the synchronicity of measures taken at the same point in time; it is also nondirectional in that the values of correlation coefficients relating one variable to another are unaffected by their sequential ordering in time (unlike regression coefficients, which are affected). Finally, the model, as applied by Rosenberg and Rosenberg, fails to take account of past educational attainment, which might account for the observed relationships between delinquency and self-esteem. All of these problems were tackled in the specification and testing by LISREL of a causal model representing the relationship between delinquency and self-esteem. LISREL (Joreskog and Sorbom, 1978, 1979) enables the investigator to test the extent to which a specified "causal path" or "structural" model of the relations between a set of "exogenous" and "endogenous" theoretical constructs fits the observed data. ${ }^{7}$ Each theoretical construct may have one or more measured indicators whose relationships to the constructs are also estimated in the model ("the measurement model"); it is also possible to vary such assumptions, typically made in path analysis, that the residuals for the constructs and/or the indicators are uncorrelated. For each model the program provides estimates of all the specified parameters not constrained to be fixed and of their standard errors, together with a maximum likelihood chi-square test of the goodness of fit of the model to the data. Because the value of chi square is almost bound to exceed chance values in large samples, the ratio of chi square to degrees of freedom $\left(\chi^{2} / \mathrm{df}\right)$ is frequently used descriptively as a criterion for comparing the extent to which different models fit the same data (Wheaton et al., 1977). Using this ratio in conjunction with the residual covariances (i.e., the differences between the observed covariances and the covariances implied by the model), a reasonably good judgment can be made of the adequacy of the model in accounting for the manifest relations in the observed data. In the present study a maximum residual difference (between correlations, rather

\footnotetext{
'Exogenous variables are analogous to the "independent" variables or predictors in multiple regression; endogenous variables are equivalent to the dependent variables, i.e., they have prior causes specified in the model.
} 
than covariances) of 0.12 was taken to indicate a reasonable fit; this corresponded roughly to a $\chi^{2} / \mathrm{df}$ ratio of 4.5 for the total sample $(N=1412)$, and 1.5 for the high self-esteem group $(N=329)$ and for the low self-esteem group $(N=308)$. Note that the ratio of $\chi^{2}$ to degrees of freedom cannot be used to compare fits between the total sample and either of the two subsamples.

A number of variants of a suitable causal model were tried, with different indicators of delinquency and various constraints imposed, until one was selected for final testing and replication across the three samples and both delinquency measures. The final model used single indicators of self-esteem and delinquency over three points in time. ${ }^{8}$ In each case delinquency was specified to be causally prior to self-esteem. Three exogenous constructs were included - a single indicator measure of SES; a past educational attainment composite comprising a measure of general ability, average grade in the previous high school year, and college plans; and a variable indicating whether the boy had been held back a year (usually because of poor grades). This last variable was included because it linked higher than average age to poor attainment - a possible predisposing factor in delinquency. In this first model, only the time 1 measures of the exogenous constructs were used. Finally, to take account of the strong "lag 2" autocorrelation ${ }^{9}$ evident from preliminary analysis, the residuals in the model for the time 1 and time 3 measures were allowed to correlate. Such a correlation can be used to assess the extent of correlated error, part of which may be a "method bias" operating across time for a particular measure (Andrews and Crandall, 1976; Wheaton et al., 1977). The goodness-of-fit statistics for the model finally chosen (model 1) are shown in Table I. It can be seen that for theft and vandalism the criteria for an acceptable fit are achieved in all groups. Thus, the maximum residual differences for Model 1 are all between 0.08 and 0.12 and the $\chi^{2} / \mathrm{df}$ ratios similarly are below 4.0 (total sample) and 1.5 (subsamples). For delinquency in school the fit is slightly less satisfactory: The $\chi^{2} / \mathrm{df}$ ratio exceeds $4.5 \mathrm{in}$ the total sample and 1.5 in the high self-esteem group, and the maximum residual differences all lie between 0.09 and 0.16 . Since the theft and vandalism measure appears to provide a better fit to the model, we will concentrate on this measure in the remainder of the paper.

\footnotetext{
"Although we refer to "single" indicators of self-esteem, delinquency, and socioeconomic status, as used in the LISREL, in fact each of these is an index derived from multiple items. 9"Autocorrelation" refers to the correlations between the different measures of the same variable over time. Lag 1 correlations refer to correlations between variables measured consecutively in time; Lag 2 correlations span three time points (i.e., from time 1 to time 3 ).
} 


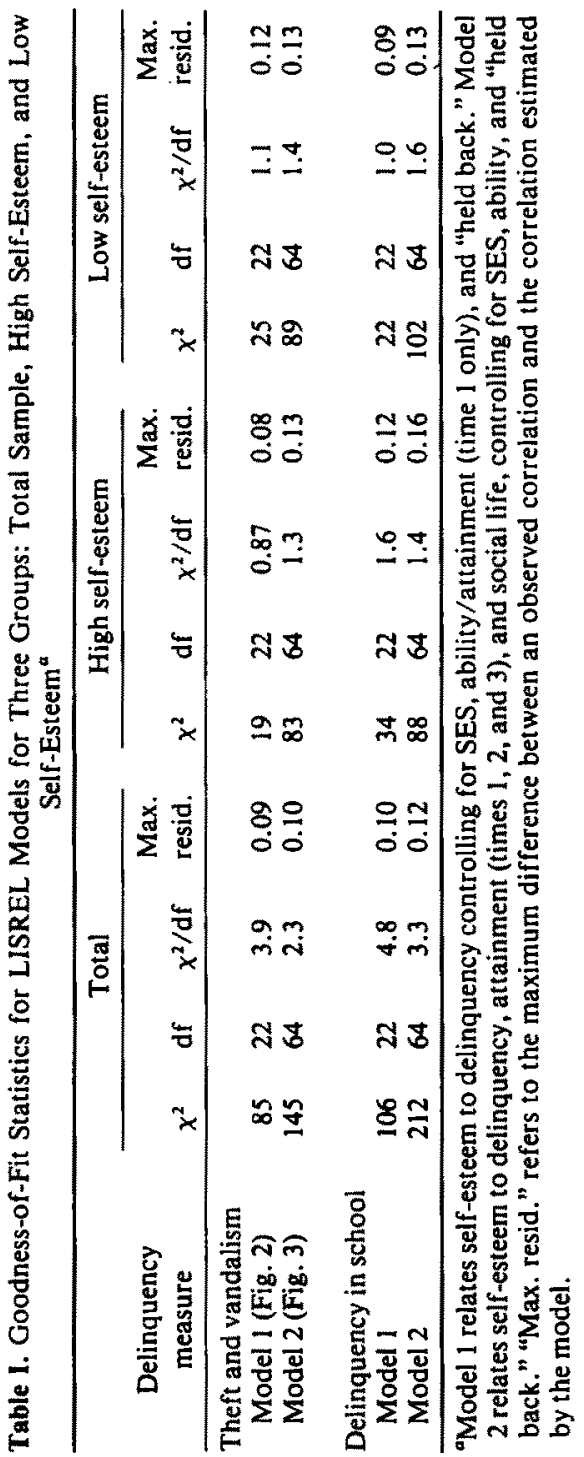


Figure 2 shows the model and the relevant parameter estimates ("path coefficients") 10 in each of three samples (total, high initial self-esteem, and low initial self-esteem) for the theft and vandalism measure. Note that the format for Figure 2 is somewhat unorthodox, in that the rectangles designating delinquency are "stretched out" in order to represent the approximate time intervals for which the delinquent behaviors were reported. Figure 2 is thus a schematic showing not only the hypothesized causal relationships but also the chronology of measurement. Note also that, as indicated in Figure 2, we assume delinquency as measured at a given time to be causally prior to self-esteem measured at the same time and causally determined by self-esteem measured at the previous time. (This differs from Figure 1, in which both delinquency and self-esteem measured at a given time are treated as synchronous.) The exogenous constructs, which are not shown in Figure 2, are posited to affect all endogenous constructs; Table II presents the relevant path coefficients from the exogenous to the endogenous constructs, and, for the endogenous constructs, the standardized residual variances. Table III presents the covariances (and, in parentheses, the corresponding correlations) between the exogenous constructs and the relevant covariances between residuals. For completeness, Table IV presents the unstandardized coefficients among the endogenous variables.

As can be seen from Figure 2 and Table IV, the most striking result for the total sample (the first figure in each group of three) and the high selfesteem group (the second figure in each group of three) is the weakness of all the paths from self-esteem to delinquency. Only one of the four is statistically significant and that one is only -0.07 (standardized); this suggests that there is little evidence in these groups of reduced self-esteem acting as a major motivator of delinquency. In fact, for the total sample and the high self-esteem group the largest standardized path from self-esteem to delinquency is only -0.07 (total sample) which compares with -0.16 (total sample) and -0.14 (high self-esteem group) for the largest paths going in the other direction (i.e., from delinquency to self-esteem). Part of the explanation can be seen in the paths running from past educational attainment to delinquency and self-esteem (Table II), some of which are substantial. On the other hand, against the views of those who argue that delinquency is primarily working class in origin (e.g., Cohen, 1955; Cloward and Ohlin, 1960; Downes, 1966), there is little evidence from Table II of any strong

\footnotetext{
${ }^{10} \mathrm{~A}$ "path coefficient" is the partial regression coefficient between a (dependent) variable and another variable postulated to cause it, taking account of all the other variables in the model that are causally prior to the dependent variable. It measures the increase in the value of the dependent variable that would be expected to accompany an increase in the causally prior variable of one unit.
} 


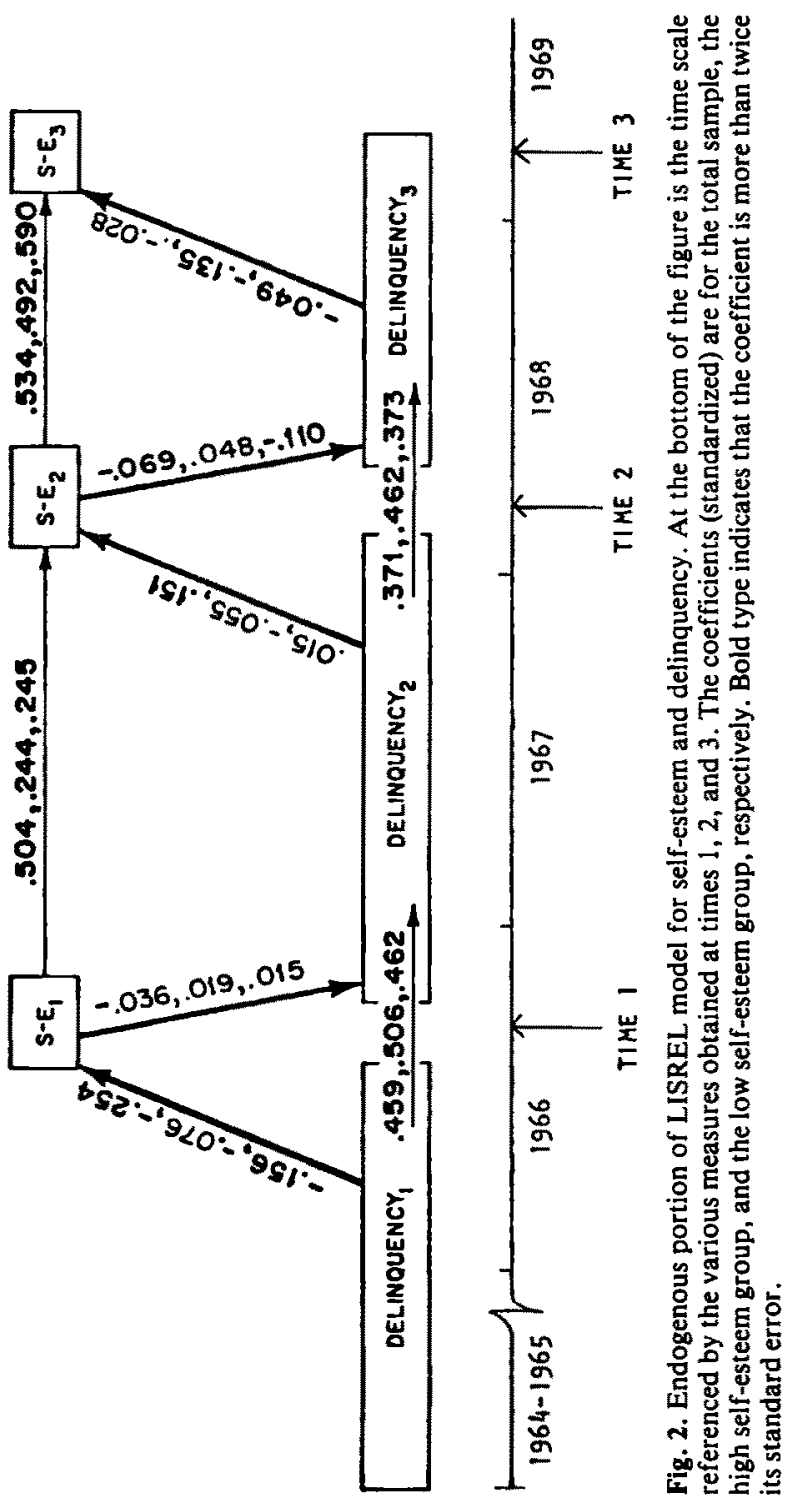




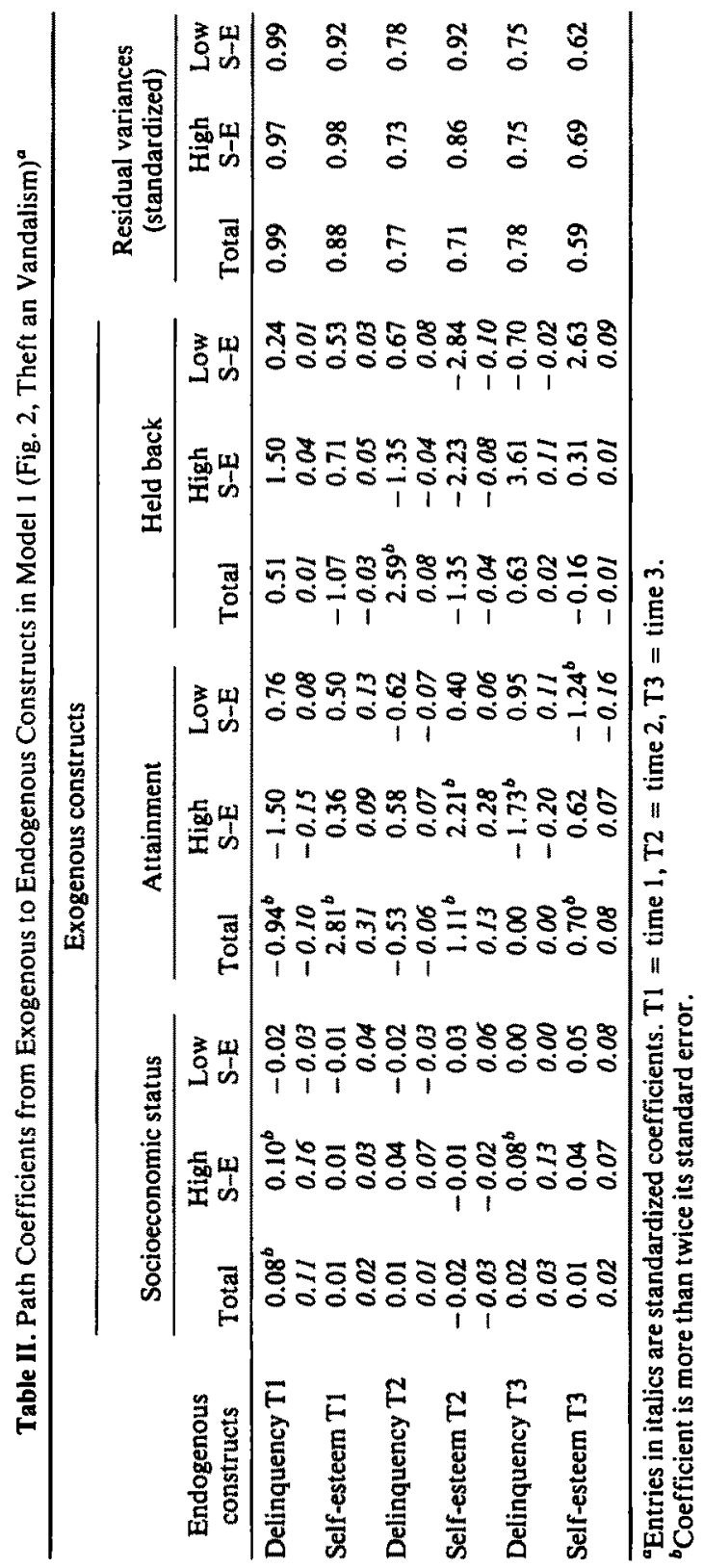


Table III. Covariances (and Correlations) Estimated in Model 1 (Fig. 2, Theft and Vandalism) ${ }^{\alpha}$

\begin{tabular}{|c|c|c|c|}
\hline Variable & $\begin{array}{c}\text { Total } \\
\text { sample } \\
(n=1412)\end{array}$ & $\begin{array}{c}\text { High } \\
\text { self-esteem } \\
(n=329)\end{array}$ & $\begin{array}{c}\text { Low } \\
\text { self-esteem } \\
(n=308)\end{array}$ \\
\hline $\begin{array}{l}\text { Delinquency } \\
\text { residual T1/T3 }\end{array}$ & $\begin{array}{l}583.89^{b} \\
(0.22)\end{array}$ & $\begin{array}{l}-45.61 \\
(-0.02)\end{array}$ & $\begin{array}{l}962.52^{b} \\
(0.29)\end{array}$ \\
\hline $\begin{array}{l}\text { Self-esteem } \\
\text { residual } \mathrm{T} 1 / \mathrm{T} 3\end{array}$ & $\begin{array}{c}428.35^{b} \\
(0.17)\end{array}$ & $\begin{array}{l}35.81 \\
(0.04)\end{array}$ & $\begin{array}{l}105.19 \\
(0.08)\end{array}$ \\
\hline $\begin{array}{l}\text { Socioeconomic status/ } \\
\text { ability-attainment }\end{array}$ & $\begin{array}{l}222.04^{b} \\
(0.52)\end{array}$ & $\begin{array}{l}158.27^{b} \\
(0.42)\end{array}$ & $\begin{array}{l}302.87^{b} \\
(0.58)\end{array}$ \\
\hline $\begin{array}{l}\text { Ability-attainment/ } \\
\text { held back }\end{array}$ & $\begin{array}{l}3.45^{b} \\
(0.42)\end{array}$ & $\begin{array}{l}2.64^{b} \\
(0.39)\end{array}$ & $\begin{array}{l}4.47^{b} \\
(0.43)\end{array}$ \\
\hline $\begin{array}{l}\text { Socioeconomic status/ } \\
\text { held back }\end{array}$ & $\begin{array}{l}28.14^{b} \\
(0.25)\end{array}$ & $\begin{array}{l}24.19^{b} \\
(0.23)\end{array}$ & $\begin{array}{l}37.78^{b} \\
(0.29)\end{array}$ \\
\hline
\end{tabular}

social class effect; the statistically significant standardized paths from socioeconomic status to delinquency are 0.16 (high self-esteem, time 1 ), 0.11 (total sample, time 1), and 0.13 (high self-esteem, time 3). (The corresponding unstandardized paths are $0.10,0.08$, and 0.08 , respectively.) Nor is there a strong tendency for boys held back a year to differ from the others with respect either to self-esteem or delinquency; the only statistically significant path from "held back" is to delinquency (time 2) in the total sample. All other standardized paths from socioeconomic status and "held back" are close to zero.

For the low self-esteem group, " relationships between the endogenous variables in the model are generally stronger and tend to support the view that delinquency is a means of restoring self-esteem. Thus, the relatively strong negative path of -0.11 from delinquency (time 1 ) to self-esteem (time 1) gives way to a significant positive path of 0.15 from delinquency (time 2) to self-esteem (time 2). It is notable too from Table III that although there is barely any lag 2 correlation between the residuals for selfesteem (time 1 and time 3) among the low self-esteem group, for delinquency there is a sizeable lag 2 correlation pointing possibly to a substantial method bias in these data, which the LISREL method allows us to control.

"We remind the reader that the "low self-esteem group" refers to the group low in self-esteem at time 1 only, not at time 2 or 3 . 
Table IV. Unstandardized Path Coefficients Among Endogenous Constructs in Model 1 (Fig. 2, Theft and Vandalism)

\begin{tabular}{|c|c|c|c|c|c|}
\hline \multirow[b]{3}{*}{ To: } & \multicolumn{5}{|c|}{ From: } \\
\hline & \multicolumn{2}{|c|}{ Time 1 (T1) } & \multicolumn{2}{|c|}{ Time 2 (T2) } & \multirow{2}{*}{$\frac{\text { Time } 3 \text { (T3 }}{\text { Delinq. }}$} \\
\hline & Delinq. & S-E & Delinq. & S-E & \\
\hline $\begin{array}{l}\text { Total sample } \\
\text { Self-esteem T1 } \\
\text { Delinquency T2 } \\
\text { Self-esteem T2 } \\
\text { Delinquency T3 } \\
\text { Self-esteem T3 }\end{array}$ & $\begin{array}{r}-0.147^{a} \\
0.428^{\circ}\end{array}$ & $\begin{array}{c}-0.036 \\
0.474^{\mathrm{a}}\end{array}$ & $\begin{array}{l}0.014 \\
0.358^{a}\end{array}$ & $\begin{array}{r}-0.070^{\mathrm{\alpha}} \\
.550^{\mathrm{\alpha}}\end{array}$ & $-0.049^{\alpha}$ \\
\hline $\begin{array}{l}\text { High S-E } \\
\text { Self-esteem T1 } \\
\text { Delinquency T2 } \\
\text { Self-esteem T2 } \\
\text { Delinquency T3 } \\
\text { Self-esteem T3 }\end{array}$ & $\begin{array}{c}-0.032 \\
0.440^{\circ}\end{array}$ & $\begin{array}{l}0.039 \\
0.459^{a}\end{array}$ & $\begin{array}{c}-0.051 \\
0.484^{a}\end{array}$ & $\begin{array}{l}0.055 \\
0.530^{a}\end{array}$ & $0.127^{a}$ \\
\hline $\begin{array}{l}\text { Low S-E } \\
\text { Self-esteem T1 } \\
\text { Delinquency T2 } \\
\text { Self-esteem T2 } \\
\text { Delinquency T3 } \\
\text { Self-esteem T3 }\end{array}$ & $\begin{array}{r}-0.107^{a} \\
0.432^{a}\end{array}$ & $\begin{array}{l}0.034 \\
0.444^{a}\end{array}$ & $\begin{array}{l}0.123^{a} \\
0.357^{\alpha}\end{array}$ & $\begin{array}{r}-0.129^{a} \\
0.636^{a}\end{array}$ & $-0.026^{\circ}$ \\
\hline
\end{tabular}

${ }^{a}$ Coefficient is more than twice its standard error. S-E = self-esteem.

All these results replicate, though in a slightly weaker form for the other delinquency indicator, "delinquency in school."

\section{Enhanced Causal Model of the Major Influences on Self-Esteem (Model 2)}

The enhanced model shown in Figure 3 is an extension of model 1 (Figure 2), this time including alongside delinquency at each time point the other two constructs, "current attainment" and "participation in teenage social life." In the case of attainment, both average grade and college plans measured at all three points in time were used as indicators; ${ }^{12}$ participation in teenage social life with a single indicator-the social/dating behavior scale - was measured only at time 1 and time 2 . Again, in order to represent the temporal sequence as realistically as possible, the figure has been constructed to show approximate time intervals covered by each measure; and this sequence was influential in determining the hypothesized causal ordering shown in Figure 3. Thus delinquency was specified as causally

\footnotetext{
${ }^{12}$ We appreciate that "college plans" is more precisely defined as an indicator of educational aspirations rather than educational attainment. Our reason for using it is that it broadens the concept of attainment to include "educational success" in a more general sense, i.e., the probability of future educational (and occupational) opportunity rooted in current educational performance.
} 


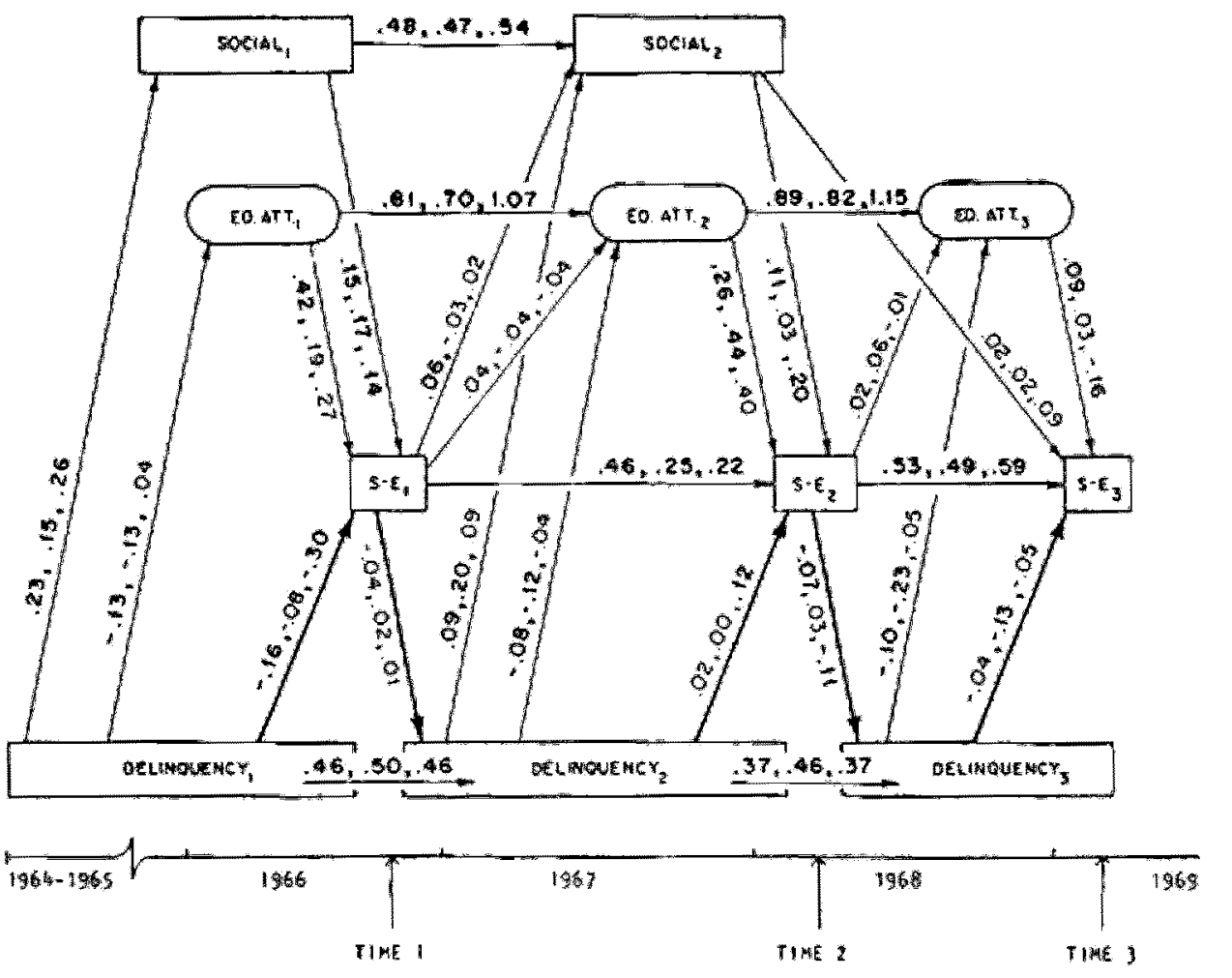

Fg. 3. Endogenous portion of LISREL model for selfesteem, delinguency, social life, and attainment. Notes: At the bottom of the figure is the time scale referenced by the various measures obtained at Times 1, 2, and 3. The coefficients (standardized) are for the total sample, the high self-esteem group, and the low self-esteem group, respectively. Bold type indicates that the coefficient is more than twice error. The arrows linking selr-esteem and delinquency are in bold to emphasize their centrality. Ovals are used to designate Attainment (ED. ATT.) because it is a theoretical unobserved construct measured by two indicators: all other constructs are observed, measured by a single indicator.

prior to both social life and attainment. The correct casual ordering for social life and attainment was more problematic. The items comprising social life referred to "average frequency" of behavior during the "school year," and attainment included as its indicators both a measure of current college plans and "average grade" over the previous year. Following an examination of the fit of models with causal ordering in one direction or another, and one in which the residuals for the two constructs were simply allowed to correlate, it was concluded that the last alternative (in which the residuals were allowed to correlate) was the most appropriate to represent the data. (The relationship between the residuals represents the degree of association left between the constructs after the effects of all other constructs causally prior to them in the model have been taken into account.) Finally all three constructs - delinquency, attainment, and social life-were considered to be causally prior to self-esteem, which represented 
feelings current at the time the data were collected. Because the social life scale was not used at time 3 , the time 2 measures had to be specified to cause both time 2 and time 3 self-esteem. (Although this breaks the symmetry of the model at time 3 , we believe that the absence of the social life variable at time 3 is unlikely to affect the magnitude of the other paths in the model.) As in Model 1, lag 2 correlations between the residuals of self-esteem and delinquency were included in the model. For one of the two indicators of attainment - average grade -in the low self-esteem group, perhaps because of an artifact, the correlation between the measures at time 1 and time 3 exceeded the correlation between these measures from time 2 to time 3.13 This presented problems in specifying correlations between residuals, and alternative ways of doing it were tried with a view to using the one that produced the best fit and the most interpretable results. The one chosen (Model 2) involved correlations between the measurement errors for each indicator of attainment from time 1 to time 2, from time 2 to time 3, and from time 1 to time 3.

In addition to these paths and those relating the different measures of each construct across time - the stabilities (Wheaton et al., 1977)-the only other paths specified in the model were between the three explanatory constructs and self-esteem within each time point, and from self-esteem to the other constructs at the next point in time. In other words, the model specified was as precise a representation as possible (with these data) of the theory that self-esteem mediates between different teenage behaviors/orientations across time.

Statistics for the goodness of fit of this model (Model 2) across the different subgroups and the two delinquency indicators are shown in Table $I$. It can be seen that the fit this time is satisfactory for "theft and vandalism"; in the total sample the $\chi^{2} / \mathrm{df}$ ratio actually drops substantially below that obtained for the simpler Model 1 (3.9 to 2.3); and all the other replications of the model come close to meeting the criteria for an acceptable fit.

The standardized path coefficients between the endogenous constructs in this model are presented in Figure 3. Table V presents the coefficients

\footnotetext{
${ }^{13}$ The fact that attainment at time 3 correlates more highly with time 1 attainment than with time 2 attainment in the low initial self-esteem group is peculiar. We have no ready explanation for the anomaly, but there are two observations we can make. One is that the low self-esteem group is on the average lower in academic competence (lower grades and lower academic ability scores), which may mean that they are "poor" respondents, with the result that their data are less "clean" and more subject to error. Another possibility is that the anomaly arises because we use pairwise deletion of data, rather than casewise. In the low self-esteem group, we lose about $10 \%$ of the cases between time I and time 3, compared to $7 \%$ in the high self-esteem group. Some of the loss is due to the fact that some respondents have dropped out of high school and some is due simply to missing data. The effect of the anomaly is to produce an estimate for the stability of attainment that is marginally greater than 1 (Figure 3). This "overestimate" is unlikely to affect any of the substantive conclusions drawn.
} 


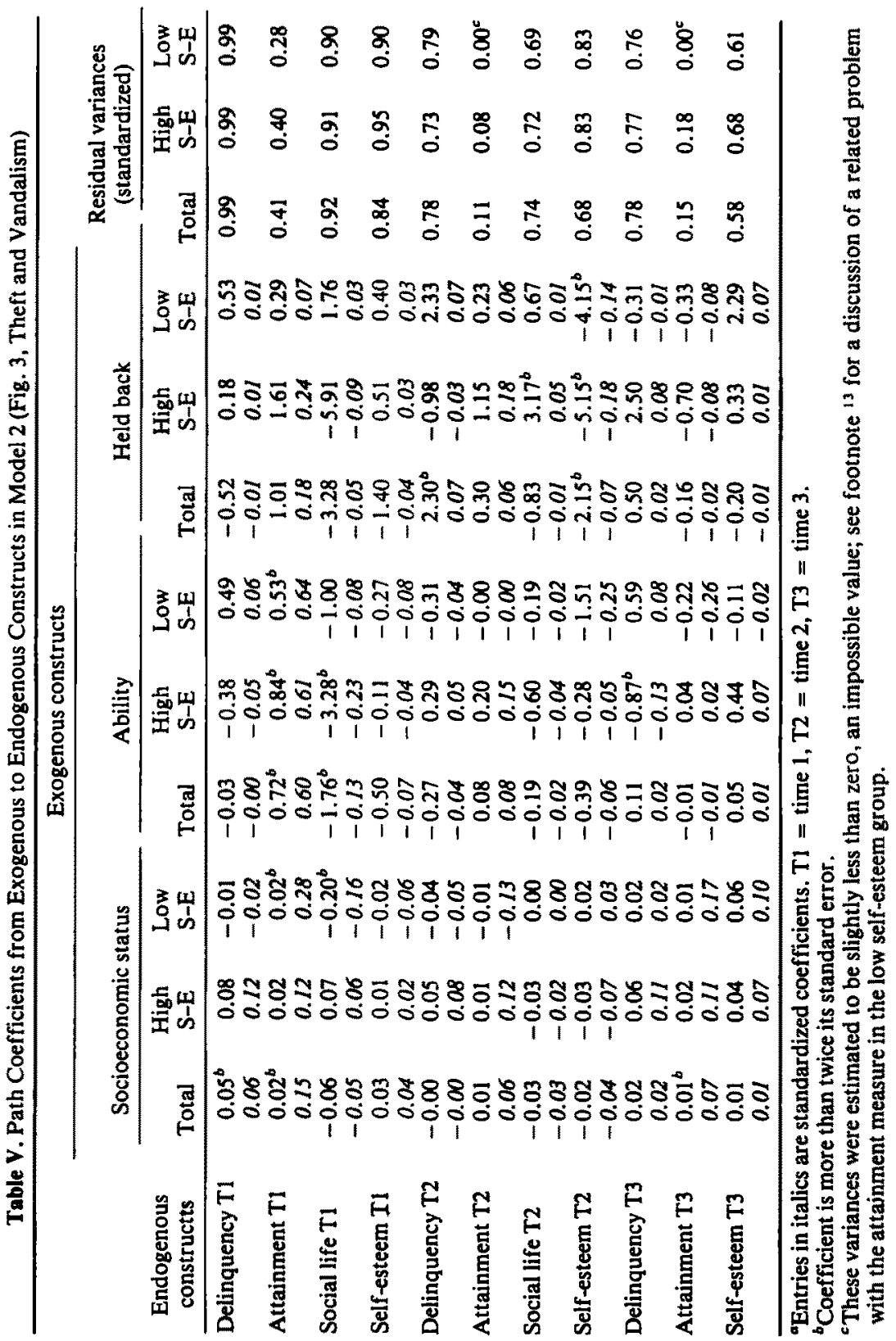


between the exogenous and endogenous constructs, and the residual variances in the endogenous constructs; Table VI presents the covariances between the exogenous constructs and the relevant covariances between residuals. And, again for completeness, Table VII presents the unstandardized coefficients among the endogenous variables. Some striking results are evident from these tables and figure. First, although there are strong paths from social life, delinquency, and particularly attainment to self-esteem at time 1 (Figure 3), the paths from self-esteem to these constructs at time 2 are all very weak. In other words, contrary to the prediction from, for example, Rosenberg and Rosenberg's conclusions, self-esteem appears to play hardly any part in mediating the effects of behavior from one time to the next. On the other hand, self-esteem is quite strongly influenced by the three prior endogenous constructs, which change in their relative importance over time. In line with predictions from Kaplan's theory, the negative path from delinquency to self-esteem at time $1(-0.30)$ changes to significantly positive at time 2 for the group initially low in self-esteem $(+0.12)$. For the total sample, the change is from -0.16 to +0.02 (the latter is not significantly different from zero), and for the group initially high in self-esteem, it changes from -0.08 to 0.00 . For all three groups, it changes again in the negative direction at time 3 , particularly for the group high in initial selfesteem $(-0.13)$. The strongest predictor of self-esteem at time 1 and time 2 for the total sample is "educational attainment"; but in line with Bachman and O'Malley's (1977) conclusions based on a different model and different analytic methods, the path weakens considerably, its value dropping from 0.42 at time 1 to 0.09 at time 3 . In contrast, social life across the two time points at which it was measured maintains its moderately positive relation to self-esteem, possibly increasing slightly for the low self-esteem group. Table $\mathrm{V}$ shows that in the total sample the paths from the exogenous to the endogenous constructs are generally weak. Thus, beyond the influence of general ability on attainment at time 1 , there is little evidence that these variables have much effect on the processes going on within the model. Finally, Table VI replicates the result from the simpler model (Model 1) regarding a possible method bias in the delinquency measure, and a similar bias in the attainment indicators.

\section{DISCUSSION AND CONCLUSIONS}

These results give only limited support to the predictions with which we started this investigation. Thus, against Rosenberg and Rosenberg's conclusion, predictions 1 and 3, (reduction in self-esteem leads consistently to greater delinquency, even when educational attainment and socioeconomic status are controlled) are not borne out by the data. On the other hand, we 
Table VI. Covariances (and Correlations) Estimated in Model 2 (Fig. 3, Theft and Vandalism) ${ }^{n}$

\begin{tabular}{lccc}
\hline \multicolumn{1}{c}{ Variable } & $\begin{array}{c}\text { Total } \\
\text { sample } \\
(n=1412)\end{array}$ & $\begin{array}{c}\text { High } \\
\text { self-esteern } \\
(n=329)\end{array}$ & $\begin{array}{c}\text { Low } \\
\text { self-esteem } \\
(n=308)\end{array}$ \\
\hline Delinquency & & & \\
residual T1/T3 & $584.74^{b}$ & -8.97 & $970.37^{b}$ \\
& $(0.22)$ & $(-0.00)$ & $(0.29)$ \\
Self-esteem & & & \\
residual T1/T3 & $404.32^{b}$ & 40.05 & 86.59 \\
& $(0.16)$ & $(0.05)$ & $(0.07)$ \\
Average grade & & & \\
residual T1/T2 & $13.31^{b}$ & $11.05^{b}$ & $13.73^{b}$ \\
& $(0.27)$ & $(0.22)$ & $(0.31)$ \\
T1/T3 & $11.34^{b}$ & $8.55^{b}$ & $10.92^{b}$ \\
T2/T3 & $(0.23)$ & $(0.17)$ & $(0.27)$ \\
College plans & $14.66^{b}$ & $12.14^{b}$ & $10.64^{b}$ \\
residual & $(0.29)$ & $(0.24)$ & $(0.25)$ \\
T1/T2 & & & \\
& & $0.03^{b}$ & $0.06^{b}$ \\
T1/T3 & $0.05^{b}$ & $(0.15)$ & $(0.23)$ \\
T2/T3 & $(0.21)$ & 0.02 & 0.01 \\
Attainment-T1/ & $0.02^{b}$ & $(0.09)$ & $(0.04)$ \\
social life-T1 & $(0.09)$ & $0.04^{b}$ & 0.02 \\
Altainment-T2/ & $0.04^{b}$ & $(0.21)$ & $(0.10)$ \\
social life-T2 & $(0.18)$ & $-104.83^{b}$ & -32.95 \\
\hline En & $-100.53^{b}$ & $(-0.12)$ & $(-0.05)$ \\
& $(-0.13)$ & 5.41 & 22.25 \\
& -13.68 & $(0.01)$ & $(-0.06)$ \\
\hline
\end{tabular}

${ }^{\alpha}$ Entries in parentheses are correlations. $\mathrm{T} 1=$ time $1, \mathrm{~T} 2=$ time $2, \mathrm{~T} 3=$ time 3.

${ }^{b}$ Coefficient is more than twice its standard error.

find some support for Kaplan's theory expressed through Prediction 2 that teenagers low in self-esteem who subsequently engage in delinquent behavior are able to restore their self-esteem. We also confirm our view, stated in Prediction 4, that other behaviors besides delinquency have an important influence on self-esteem, differing in importance as boys get older.

The main conclusion to be drawn from these results is that after entry into tenth grade, delinquency, attainment, and social life influence each other and affect self-esteem-but the influence of attainment declines during the high school years. Moreover, contrary to Hypothesis 2, the major hypothesis with which we started this investigation, self-esteem appears to play little part in influencing the teenage behaviors/orientations that follow it in time; these seem to occur largely as a part of a continuing pattern of development influenced by variables not included in the model. 


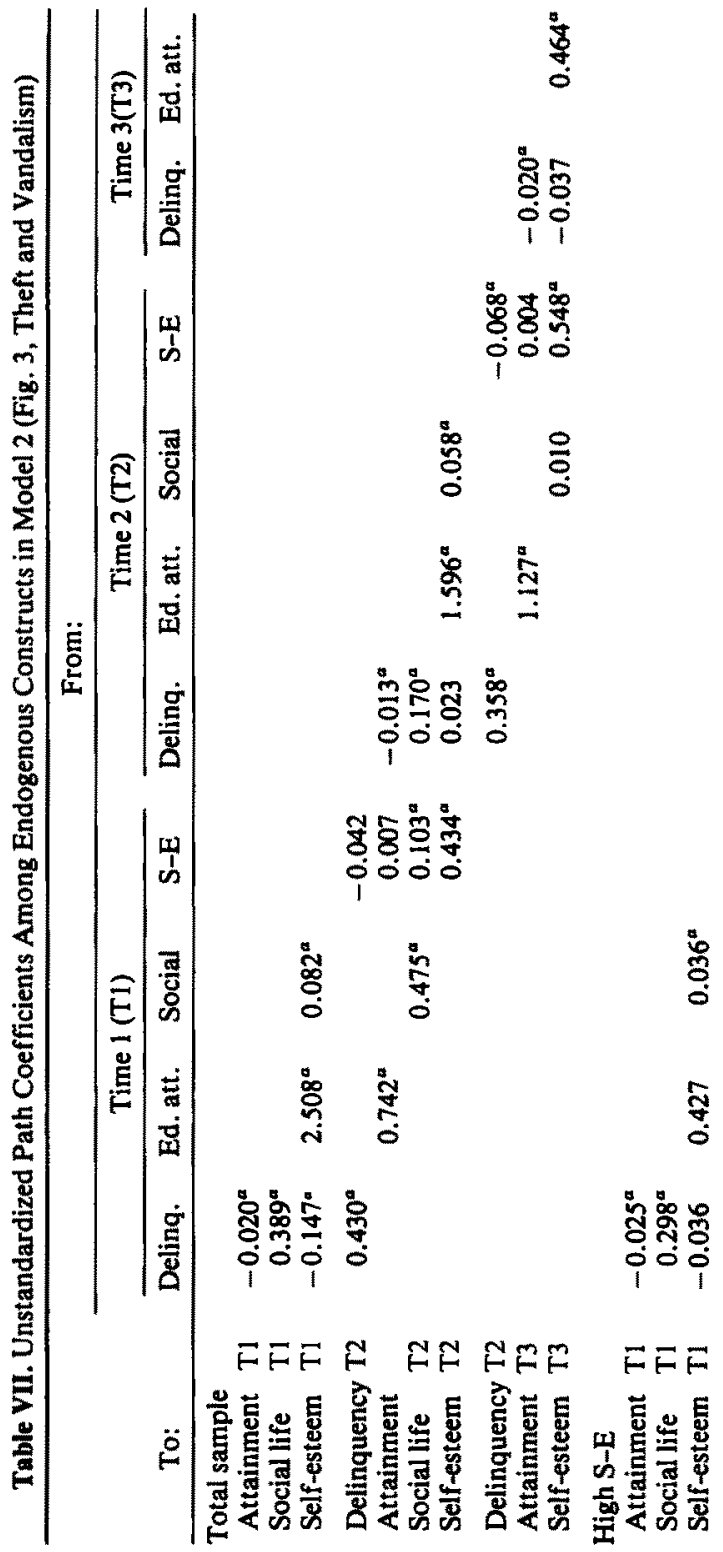




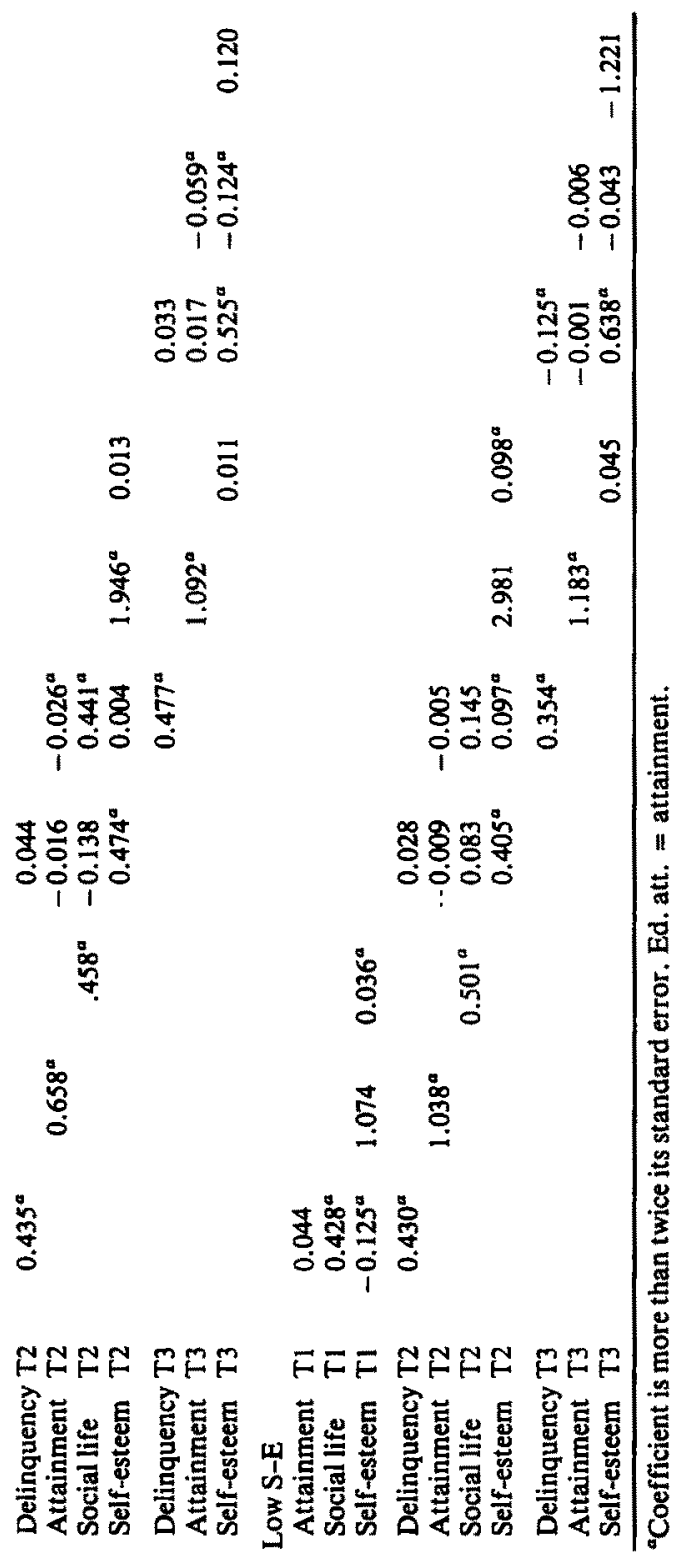


On the other hand, Hypothesis 3 (delinquent behaviors can help to boost self-esteem) is supported by the results. As Kaplan predicts, boys suffering from the biggest reduction in self-esteem when entering high school seem able to restore self-esteem by engaging in delinquent behavior.

These findings prompt several speculations about the role of global self-esteem in teenage behavior. Although the postulated effect of delinquency in restoring self-esteem to those among whom it is lowest does occur, the role of self-esteem as a motivator in future delinquency or behavior in the other major areas of teenage achievement at school and in the teenage culture outside is questionable. It seems that changes in selfesteem accompany changes in behavior or arise out of them (e.g., school failure), but any effects of self-esteem on subsequent behavior are either dissipated over time or are mediated by other variables more directly concerned with the behavior itself. This latter possibility is in line with recent arguments by Bynner (1979) that self-esteem is gained or lost on at least three major dimensions of adolescent values - "successfulness," "toughness," and "sexual precocity"-and that loss of esteem on any one dimension is generally compensated for by a gain on another, in order that something like an "optimum" or at least "minimally acceptable " level of self-esteem can be maintained. In terms of this reasoning, poor grades may produce loss of status at school, which may be countered by exhibitions of masculine toughness there or sexual precocity prized in the teenage world outside the school. On this basis, loss of overall self-esteem may be simply a reflection of a mood connected with the belief that one or another status goal is, at least temporarily, out of reach. As behavior and consequently self-perception change (e.g., after taking up smoking), this imbalance in self-esteem is restored; but the mechanism is via the particular component of self-esteem related to the behavior (e.g., smoking - toughness), not selfesteem as a whole (see also Bynner, 1969, 1979.)

Particularly notable in the present results is the weakening influence of attainment on self-esteem as boys progress through high school. Bachman and O'Malley (1977) point to a growing autonomy in the self-concept during this period, which is only marginally affected by subsequent experiences which might be cause for self-devaluing (e.g., unemployment; see also O'Malley and Bachman, 1979). In other words, during the early teens the "adolescent crisis" is at its height, and the pressures of educational attainment and delinquent associations on self-esteem are at their strongest. "Dropout" may be one response, particularly among working class boys (Elliot and Voss, 1972). By the time the others leave high school, most have come to terms with the level of educational success they have been able to achieve, and their need for the delinquent response to restore self-esteem seems to disappear. 
We should emphasize that our sample was restricted to boys and we have no way of telling whether these conclusions would apply equally to girls. Certainly, the kind of delinquent behavior we have been concerned with (e.g., "theft and vandalism") is more common among males than females. On the other hand, deviant responses by girls, typically expressed through precocious sexual behavior (bound up more with our variable "participation in social life") have been shown to accompany reduction in self-esteem (Kaplan, 1977, 1978; Gold, 1978). It seems likely, therefore, that as the pressure on girls to succeed at school is reduced, their need to seek alternative (deviant) ways of restoring self-esteem similarly declines.

With a few exceptions, most of the path coefficients reported here are relatively small; and we have to consider that one cause of this could be the unreliability of the measures employed. However, we suspect that even if corrections for attenuation were made to take account of unreliability, the basic relationships across time between self-esteem and other measures would not markedly change. Another source of possible distortion in the results is the inevitable misclassification of some respondents into initial high and low self-esteem groups, brought about by the less than perfect reliability of the self-esteem measure (coefficient alpha in the order of $0.75-0.80$ ). Our conclusion is that any such misclassification will make the characteristics of the subsample more like those of the total sample. This suggests that the size of the striking change at time 2 from negative to positive of the coefficient for the path from delinquency to self-esteem, which occurs only in the low self-esteem group, probably underestimates the true effect.

On the assumption that the pattern of causal relationships shown in Figure 3 is a reasonably accurate one, the following two points are worth directing at educators and others concerned with teenagers' adjustment problems.

First, the treatment of delinquency in isolation from the broader teenage culture of which it forms a part overlooks the point, suggested by the positive paths from other variables to self-esteem (Model 2), that poor school performers may gain self-esteem from other pursuits and achievements than those defined as delinquent. Schools need to recognize the positive benefits of many of these teenage culture activities rather than dismiss them as antithetical to school aims. Second, following Golds's arguments (1978), is the need to reduce the competitive pressure on teenagers to achieve school-defined goals at all costs. The continued damage to self-esteem arising from educational failure in high school, though not necessarily leading to delinquency, can only be viewed as damaging to the mental health of many teenagers whose worth has to be recognized in other ways. 


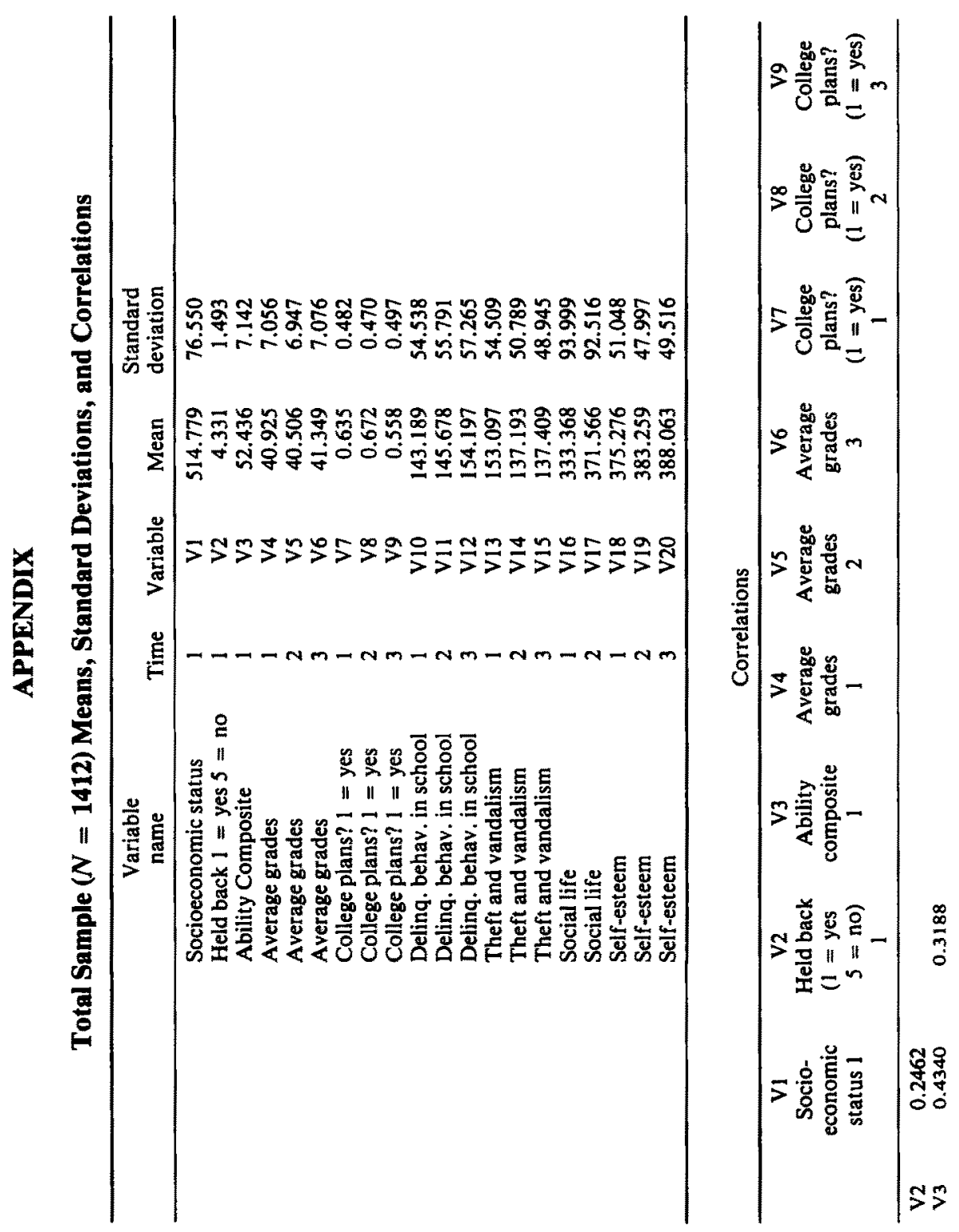




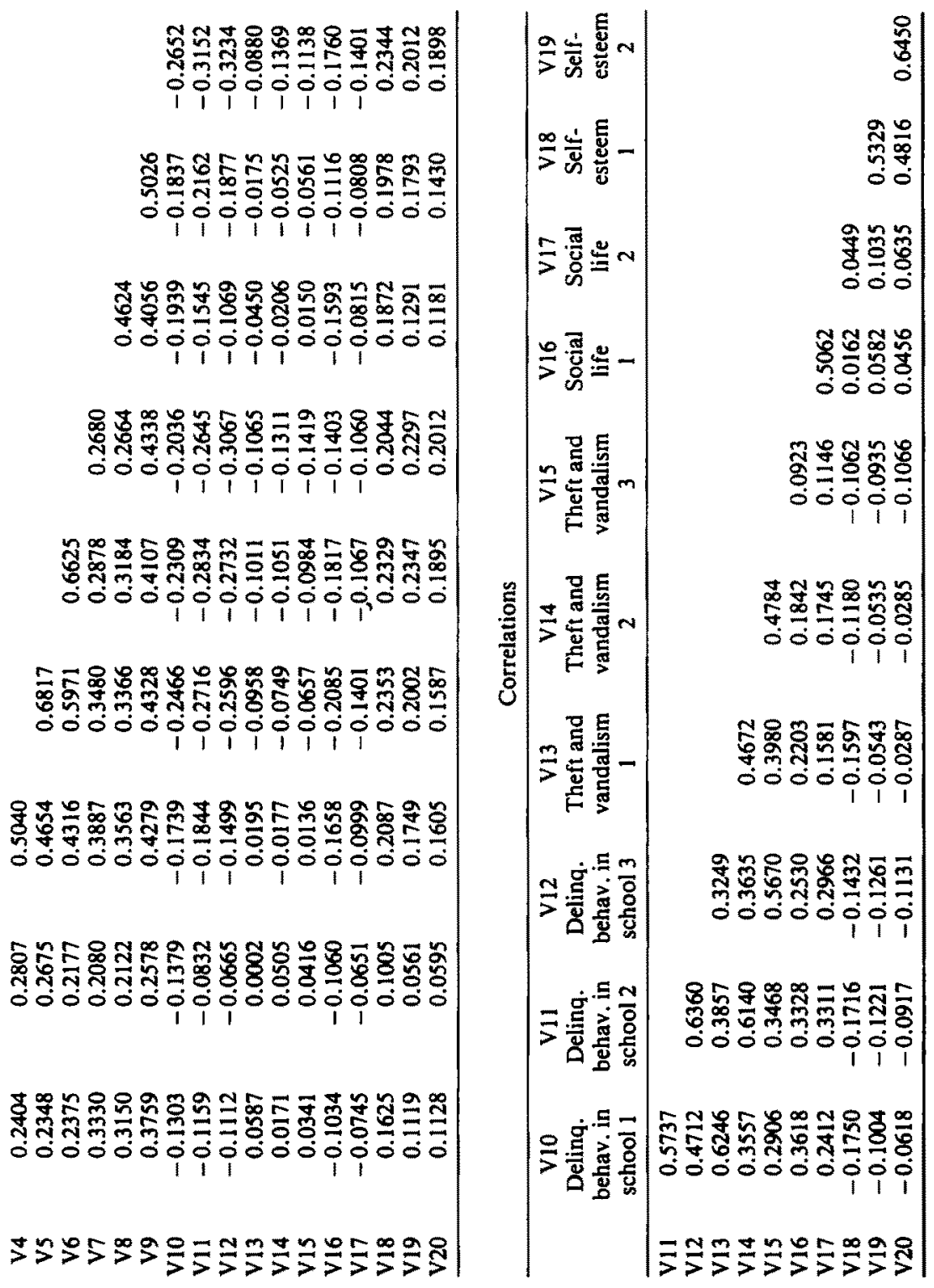




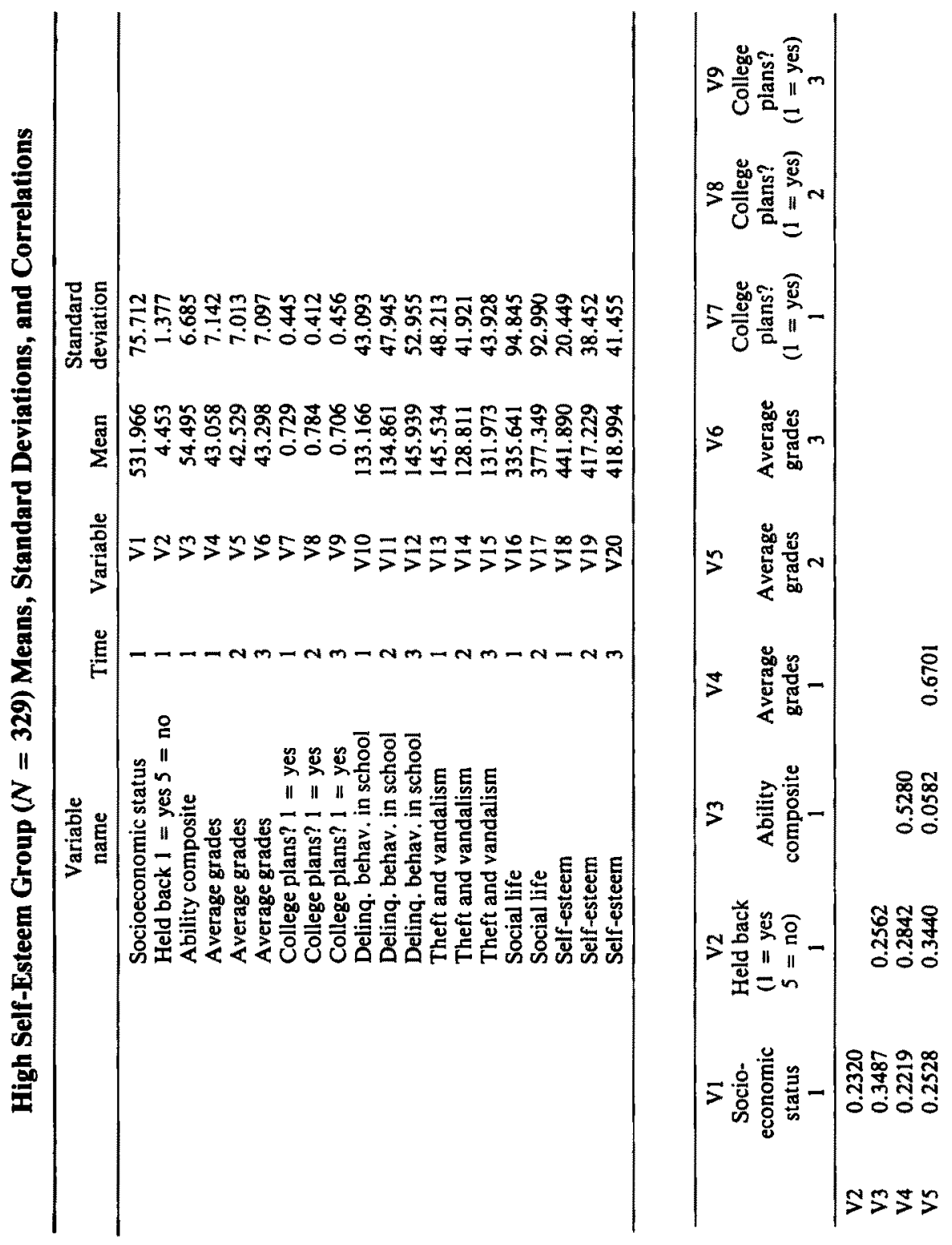




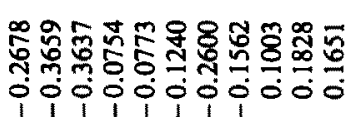

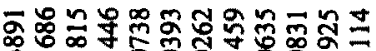
10

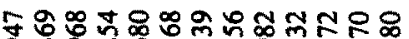
\$ - 000000000000

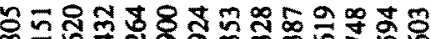

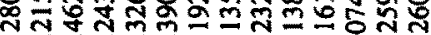

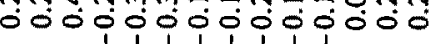

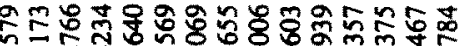

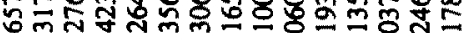
000 0000000000

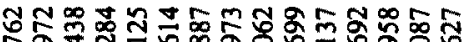
的武

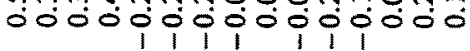

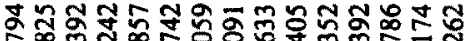

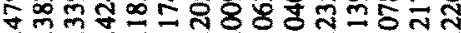

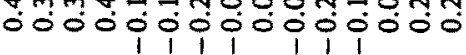

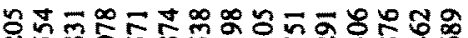

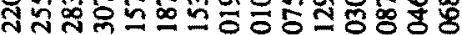
○00000000000

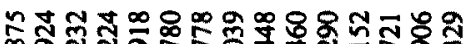

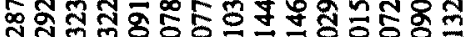

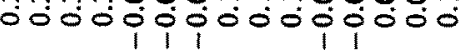

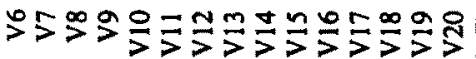

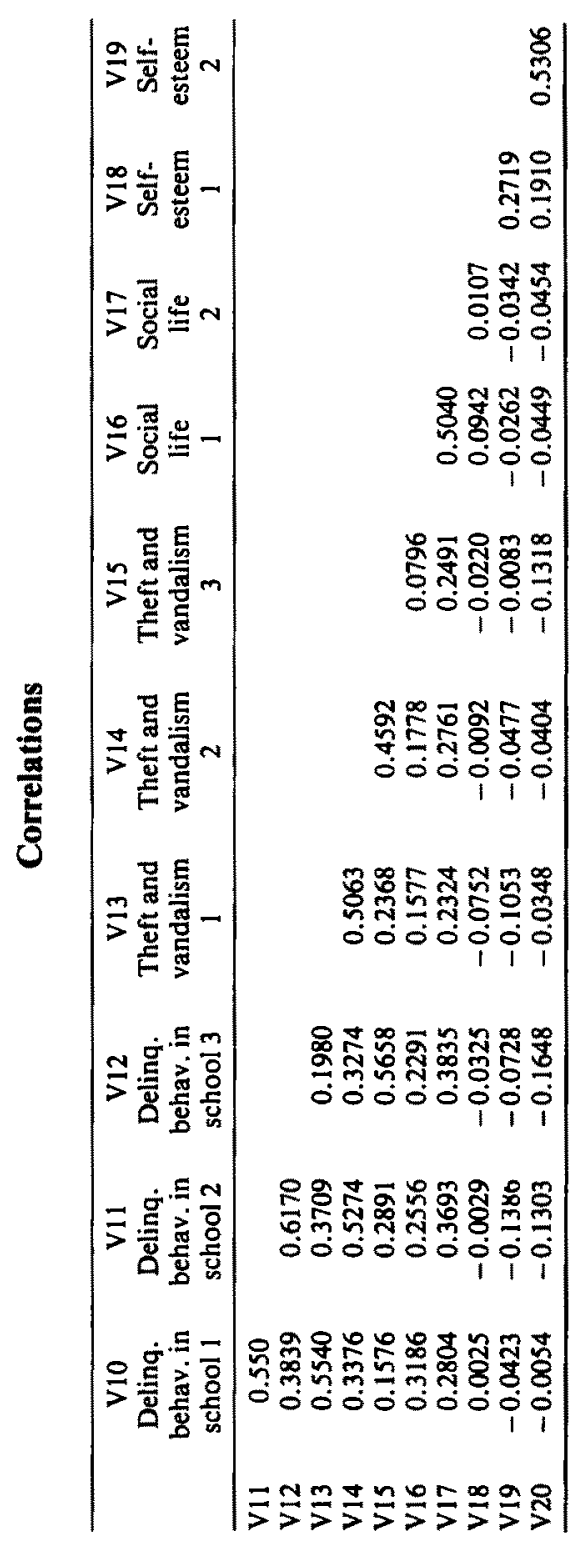




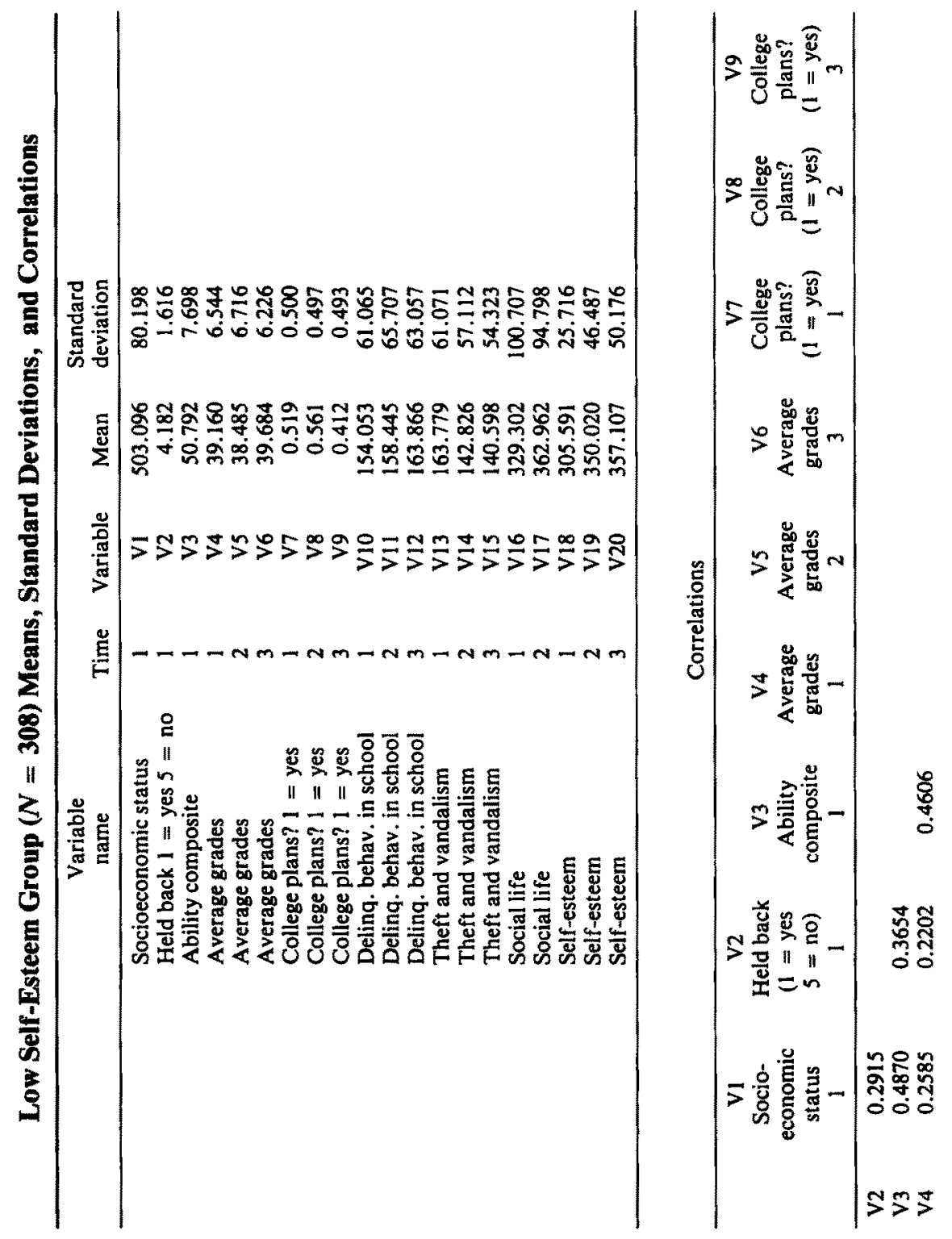




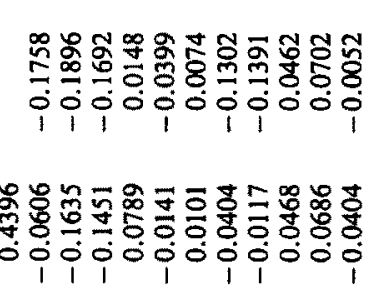

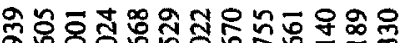
90 $000_{1}^{\circ} 0_{1}^{\circ} 0_{1}^{\circ} 0_{1}^{\circ} 0_{1}^{\circ} 0^{\circ}$

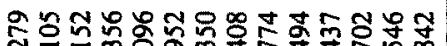
สิส

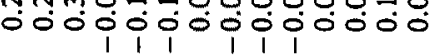

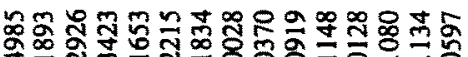
+ ooo pipipipooso

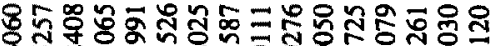
○一

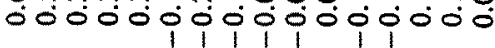

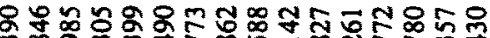

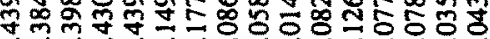
ó000

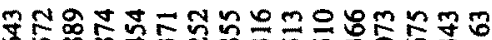

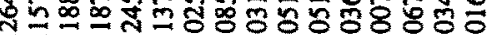
०000000000000000

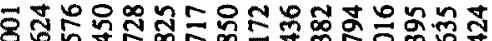

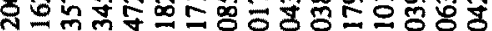
00000000000000

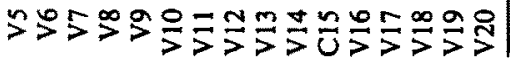

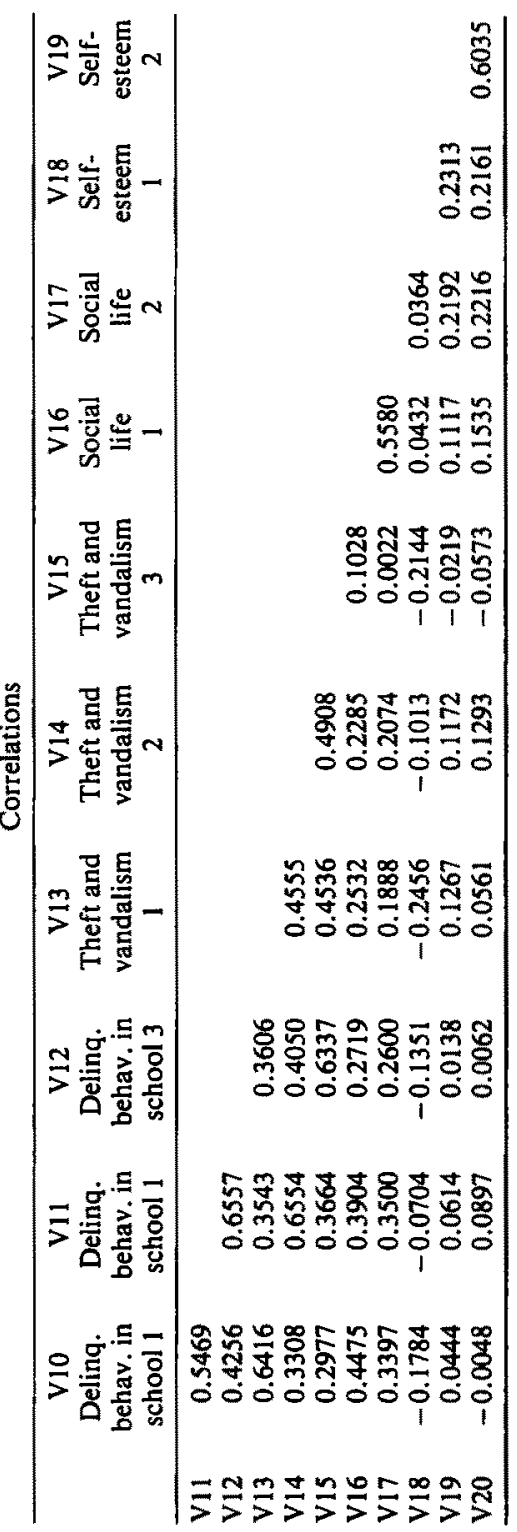




\section{ACKNOWLEDGMENTS}

The authors wish to thank Mary Grace Moore, Research Associate at the Institute for Social Research, for carrying out the extensive computing analyses for this study, and the following colleagues for their valuable comments on an earlier draft on this paper: Frank Andrews, Martin Gold, Lynn Kahle, Willard Rodgers, and Morris Rosenberg. We would also like to thank the anonymous reviewers, who provided some useful suggestions.

\section{REFERENCES}

Ammons, R. B., and Ammons, C H. (1962). The Quick Test (QT): Provisional manual. Psychol. Rep. 11:111-161. (Monogr. Suppl: I-VIl.)

Andrews, F. M., and Crandall, R. (1976). The validity of self-reported measures of wellbeing. Soc. Indicat. Res. 3: 1-14.

Bachman, J. G. (1970). Youth in Transition, Volume II: The Impact of Family Background and Intelligence on Tenth-Grade Boys, Institute for Social Research, Ann Arbor, Mich.

Bachman, J. G., and O'Malley, P. M. (1977). Self-esteem in young men: A longitudinal analysis of the impact of educational and occupational attainment. J. Personal. Soc. Psychol. 35: 365-380.

Bachman, J. G., O'Malley, P. M., and Johnston, J. (1978). Youth in Transition, Volume VI: Adolescence to Adulthood-Change and Stability in the Lives of Young Men, Institute for Social Research, Ann Arbor, Mich.

Bynner, J. M. (1969). The Young Smoker, Her Majesty's Stationery Office, London.

Bynner, J. M. (1979). Adolescent culture and delinquent values. Mimeographed.

Cloward, R. A., and Ohlin, L. E. (1960). Delinquency and Opportunity, Free Press, New York.

Cobb, S., Brooks, G. H., Kasl, S. V., and Connelly, W. E. (1966). The health of people changing jobs: A description of a longitudinal study. Am. J. Publ. Hlth. 56: 1476-1481.

Cohen, A. K. (1955). Delinquent Boys, Free Press, New York.

Coopersmith, S. (1967). The Antecedents of Self-Esteem, Freeman, San Francisco.

Downes, D. M. (1966). The Delinquent Solution: A Study in Subcultural Theory, Collier Macmillan, London.

Duncan, O. D. (1961). A socioeconomic index for all occupations, and properties and characteristics of the socioeconomic index. In Reiss, A. J. (ed.), Occupations and Social Status, Free Press, New York.

Elliott, D. S., and Voss, H. L. (1974). Delinquency and Drop-Out, Heath, Lexington, Mass.

Gates, A. I. (1958). Gates Reading Survey-Form I, Teachers College, Columbia University, New York.

Gold, M. (1978). Self-esteem and delinquent behavior: A theory of alternative schools. Crime Delinquen. Literat. July, 290-308.

Gold, M., and Mann, D. (1972). Delinquency as defense. Am. J. Orthopsychiat. 42: 463-469.

Gold, M., and Reimer, D. J. (1975). Changing patterns of delinquency. Crime Delinquen. Literat. December: 483-513.

Joreskog, K. G., and Sorbom, D. (1978). LISREL IV: Analysis of Linear Structural Relationships by the Method of Meximum Likelihood, Users' Guide, National Educational Resources, Chicago.

Joreskog, K. G., and Sorbom, D. (1979). Advances in Factor Analysis and Structural Equation Models, Abt. Associates, Cambridge, Mass.

Kaplan, H. B. (1975). Self Attitudes and Deviant Behavior, Goodyear, Pacific Palisades, Calif. 
Kaplan, H. B. (1977). Increase in self-rejection and continuing/discontinued deviant response. J. Youth Adoles. 6: 77-87.

Kaplan, H. B. (1978). Deviant behavior and self-enhancement in adolescence. J. Youth Adoles. 7: 253-277.

Matza, D. (1964). Delinquency and Drift, Wiley, New York.

McCord, J. (1978). Comments on "Self-esteem and delinquency." J. Youth Adoles. 7: 291-293.

Mead, G. H. (1934). Mind, Self and Society, University of Chicago Press, Chicago.

O'Maliey, P. M., and Bachman, J. G. (1979). Self-esteem and education: Sex and cohort comparisons among high school seniors. J. Personal. Soc. Psychol. 37: 1153-1159.

Pelz, D. C., and Andrews, R. M. (1964). Detecting causal priorities in panel data. Am. Sociol. Rev. 29: 836-848.

Rosenberg, F. R., and Rosenberg, M. (1978a). Self-esteem and delinquency. Journal of Youth and Adolescence 7: 279-291.

Rosenberg, F. R., and Rosenberg, M. (1979b). Reply to Joan McCord's comment. J. Youth Adoles. 7: 293-294.

Rosenberg, M. (1965). Society and the Adolescent Self-Image, Princeton University Press, Princeton, N.J.

Wheaton, B., Muthen, B., Alwin, D. E., and Summers, G. F. (1977). Assessing reliability and stability in panel models. In Heise, D. R. (ed.), Sociological Methodology, 1977, Jossey-Bass, San Francisco. 